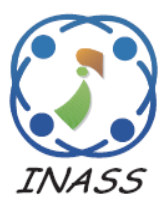

\title{
Evolutionary Programming Approach for Deregulated Power Systems to Optimal Positioning of FACTS Devices
}

\author{
Siva Kumar Kondakavali ${ }^{1 *} \quad$ Bramhananda Reddy Teegala $^{2} \quad$ Anjaneyulu Ksr $^{1}$ \\ ${ }^{1}$ Jawaharlal Nehru Technological University, Anantapur, Andhra Pradesh, India \\ ${ }^{2}$ G. Pulla Reddy Engineering College, Kurnool, Andhra Pradesh, India \\ * Corresponding author's Email: ksivakumarjntuphd@gmail.com
}

\begin{abstract}
From past decade, the major issues involved in deregulated power systems are branch loading and voltage stability. To address this issue, in this paper an evolutionary programming algorithm was proposed for optimal positioning of FACTS devices. The Evolutionary Programming algorithm considers the FACTS devices and line numbers to generate the population. The proposed approach considered three objectives for optimality such as maximization of branch loading, maximization of the voltage stability and minimization of the power loss. The proposed algorithm's performance is compared with the conventional genetic algorithm and the simulation is carried by MATLAB with different cases. With the simultaneous operations of branch loading, voltage stability and loss minimization, the branch loading is increased by $9.6 \%$ and the voltage stability is increased by $2.3 \%$ and the loss is reduced by $4.8 \%$. The result shows the performance of the proposed model.
\end{abstract}

Keywords: Evolutionary programming, Genetic algorithm, FACTS devices, Optimization.

\section{Introduction}

All The open choose policy is applied in the transmission system after the deregulation of transmission lines. Due to the abnormal selection policy, the congestion is created on the transmission lines [1-3]. An abnormal usage of transmission lines is also another cause for congestion, and it reaches to the power transfer limit. These types of issues will be addressed by introducing FACTS devices in power systems. These FACTS devices have the ability to control the various parameters in a transmission network for power systems. FACTS devices are classified as UPFC (Unified power flow controller), SVC (Static VAR Compensator) and TCSC (Thyristor Controlled Series Capacitor). In order to compensate to the inductive reactance, the TCSC is connected in series within the branch. The generation of transmission line reactive power is carried out by SVC with respect to thyristor controlled circuits. The parameters like, voltage phase and impedance is controlled by UPSC. In [4], the optimal location of TCSC in Transmission lines was proposed, which are concentrated on reducing the power losses. For improving the social welfare cost and reducing the power loss in the network, the TCSC is introduced into the deregulated market for congestion management [5]. In [6], the FACTS device optimization is proposed by using genetic algorithm. In [7] and [8], the genetic algorithm introduces optimal allocation for multiple types of FACTS. But, the complex procedure of genetic algorithm creates some voltage loss in the power lines. In [9], for solving the bid based economic dispatch problem the authors proposed the interior point algorithm. To reduce the congestion in power system networks in deregulated markets, TCSC is introduced in [10]. This procedure doesn't consider the real time environment factors such as deregulated power supply in the network. For security constraints in the economic dispatch, the linear programming model is introduced in [11]. The linear programming model creates overhead in the optimization mechanism. In [12] and [13], the optimal placement of UPFC and SVC is placed in the network to reduce the congestion, but these methods don't consider the 
TCSC for the congestion management. In [14], the authors proposed genetic algorithm with the combination of fuzzy logic for solving the congestion problem in power systems. The impedance and voltage phase are not considered as objectives in the proposed model. Evolutionary programming and differential evolution is proposed in [15] [16] and [17] without contingency for optimal positioning of FACTS. These models are only single objective mechanisms.

This paper presents the Evolutionary programming approach for FACTS Devices. The Evolutionary programming approach contains heuristic mechanisms to solve the optimization problems effectively. The mathematical formulation for positioning the FACTS devices on IEEE30 bus system are discussed in detail. The simulations obtained for both Evolutionary Algorithm and Genetic Algorithm proves the efficiency.

The remaining paper is organized with the following sections. Section 2 describes about the designing of FACTS devices. Section 3 discuss about the conventional genetic algorithm and their drawbacks. Section 4 explains about the proposed approach to the defined objectives. Section 5 describes about the objectives of the optimality. Section 6 explains about the experimental evaluation of the proposed optimality model and finally, section 7 concludes the paper.

\section{Design of FACTS Devices}

All One of the major issues faced by the power transmission industries related to supply and demand are

$>$ In large power distribution models, stability is the major factor. It causes several problems in blackouts and power distribution leads to loss.

According to the demand, the transmission and distribution of power is based.

\subsection{Thyrister controlled Series Capacitor:}

The TCSC is capable of controlling the power over the ac transmissions [18]. The TCSC contains the series capacitor ' $\mathrm{C}$ ' which is connected parallel to the controlled reactor ' $\mathrm{L}$ ' which is given in Figure 1. The main reason for introducing TCSC is, to regulate the line reactance with the help of inductance accumulation and reactance accumulation which is shown in Figure 2.
The reactive power injections of line attached between two buses $i$ and $j$ having series impedance $r_{i j}$ $+\mathrm{j} \mathrm{y}_{\mathrm{ij}}$ and the capacitor ' $\mathrm{C}$ ' is connected parallel to the TCSC controlled reactor $\mathrm{L}$ as which is shown in Figure 1. The role of TCSC in the power line is, to adjust the reactance of line in the network by accumulating either inductive or reactive element which is shown in Figure 2.

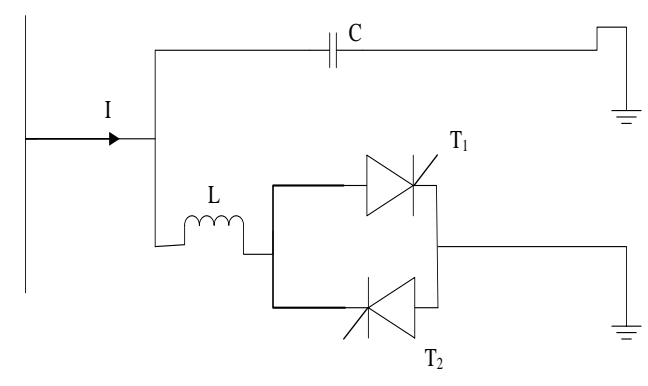

Figure.1 Diagram of TCSC

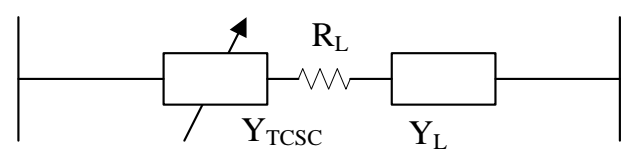

Figure.2 TCSC in Transmission Line

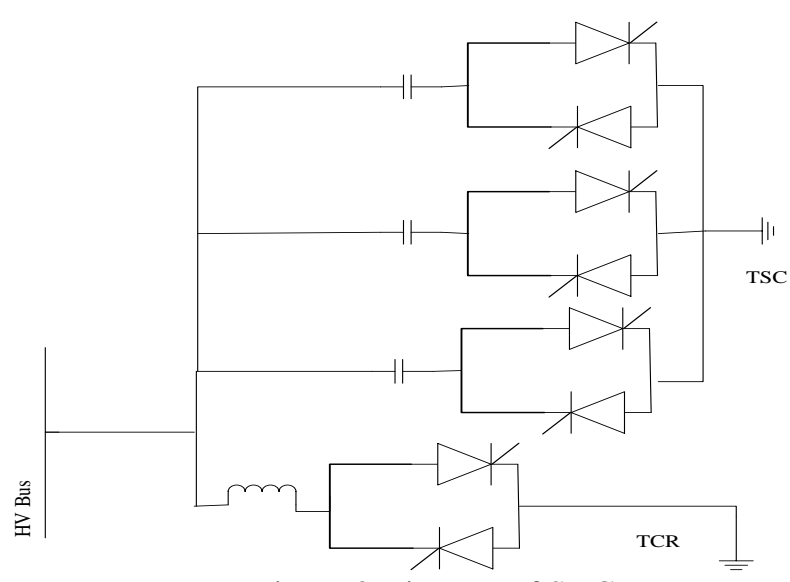

Figure.3 Diagram of SVC

$$
\begin{gathered}
Q_{i j}=-v_{i}^{2} \theta b_{i j}-v_{i} v_{j}\left[\theta g_{i j} \sin \left(\delta_{i}-\delta_{j}\right)\right. \\
\left.-b_{i j} \cos \left(\delta_{i}-\delta_{j}\right)\right]
\end{gathered}
$$

Where

$$
\begin{aligned}
& \theta g_{i j}=\frac{y_{c} r_{i j}\left(y_{c}-2 x_{i j}\right)}{\left(r_{i j}^{2}+y_{i j}^{2}\right)\left\{r_{i j}^{2}+\left(y_{i j}-y_{c}\right)^{2}\right\}} \\
& b_{i j}=\frac{-\left(y_{i j}-y_{T C S C}\right)}{r_{i j}^{2}+\left\{y_{i j}-y_{T C S C}\right\}^{2}}
\end{aligned}
$$




$$
\theta b_{i j}=-\frac{y_{c} r_{i j}\left(y_{c}-2 x_{i j}\right)}{\left(r_{i j}^{2}+y_{i j}^{2}\right)\left\{r_{i j}^{2}+\left(y_{i j}-y_{c}\right)^{2}\right\}}
$$

The controllable reactance $y_{c}$ is used in equation 1 , which is a power line function of TCSC. From equation 1 to 4 , the reactive power injections of TCSC from bus $i$ to bus $j$ is derived. The TCSC range in the transmission line is formulated in the Equation 5 , and $Y_{L}$ is the reactance of the line in the network.

$$
-0.7 \mathrm{Y}_{\mathrm{L}}<\mathrm{Y}_{\mathrm{TCSC}}<0.2 \mathrm{Y}_{\mathrm{L}}
$$

The ideal positioning of TCSC device is performed by Evolutionary Programming (EP) algorithm which is discussed in section 4 .

\subsection{Static VAR Compensator:}

To control the precise parameters in the output of the power system networks, the model uses the SVC, which is a static VAR generator [19] [20]. In the power system networks, the model uses VAR (Volt Ampere reactive), to create the flux in the machineries like induction motors, transformers etc. The transmission network terminal voltage is controlled by the SVC which is shown in Figure 3. The placement of SVC is vital in the network. Most probably, the SVC is placed in the bus in the center of the transmission lines or at the end. The basic purpose of SVC is to inject or to absorb the reactive power. If the load of the bus is high, the inductive SVCs acts as capacitive and inject the reactive power. If the model contains high reactive power, SVCs acts as inductive and absorbs the reactive power. By this mechanism, the model has control over the voltage. The operation of SVCs is crucial at the time of high voltage drops.

The limit of reactive power for the SVCs is given in equation 6. The optimal SVCs selection is based on the Evolutionary Programming.

$$
-200 \mathrm{VAR} \leq \mathrm{Q}_{\mathrm{SVC}} \leq 200 \mathrm{VAR}
$$

\subsection{Unified Power Flow Controller:}

The unified power flow controller (UPFC) is an efficient multi-purpose FACTS controller, which handles the physical and reactive power in the transmission network rapidly and individually [21]. It is modelled based on the combination of two FACT devices such as TCSC and SVC that are connected to the bus in the network. It will control the parameters like voltage phase angle and the impedance of the network [8]. The limits for UPSC are given in equation 5 and equation 6.

\section{Conventional Genetic Algorithm}

The conventional genetic algorithm (GA) [26] is the general mechanism applied for the global search and selection technique. The GA starts with the population selection, cross over and mutation is applied for the generation of best population from the selected population. Algorithm 1 shows the implementation procedure of GA approach.

Algorithm 1: Conventional Genetic Algorithm

Input: Number of FACTS devices, possible locations for the fact devices, number of individuals for the population.

Output: Best individual

Begin

Step 1: Read the branch data from the input

Step 2: generate the initial population

Step 3: Arrange the FACTS locations

Step 4: Calculate the fitness of each individual

Step 5: If the best individual is found

Select the individual as best population

Otherwise

Create new population using reproduction, cross over and mutation

Goto step 2

End

In the algorithm 1, as an initial population, the number of FACTS devices is selected and calculated the fitness function for each device, by placing them in random locations. If the suitable results had found, then select the FACTS combination as a best population. Otherwise, create the new population using the reproduction phase. The reproduction phase contains both the cross over and mutation. The cons of the conventional GA approach are: it undergoes unlimited iterations for finding the best solution and it decreases the overall performance of the model. To overcome these issues, the Evolutionary programming approach was introduced.

\section{Evolutionary Programming Approach}

The Evolutionary programming is one of the effective optimization techniques that include initialization, mutation and competition. A set of parent population is selected for mutation. After applying the mutation, the new population is generated. A fitness function is calculated for developing the new generation of population. The fitness function will act as an objective function to the problem. The candidates in the set of newly generated population will participate in the 
competition scheme [22]. The winning candidates will form a new set of generation. This will be evolved as a global solution.

A global optimization problem is defined as the maximization of branch loading, maximization of the voltage stability and minimization of the power loss. The function for the global optimization is given as

Problem : $f(x)=\left\{\max (\beta), \max (v), \min \left(J_{1}\right)\right\}$

Subject to $1.05 \geq \mathrm{V}_{\mathrm{z}} \leq 0.95$,

Where $f(x)$ is the objective function, which is need to be continued until it reaches to the optimal solution. The evolutionary programming approach is used to find the optimal positioning of FACTS devices. The self-adaptive mutation approach with evolutionary programming approach is performed well when compared to without self-mutation approach. The proposed algorithm is given in algorithm 2.

Algorithm 2: Evolutionary Programming

Input: Facts devices and line numbers

Output: optimal pair

Begin

Step 1: select the initial population randomly by placing the FACTS devices on the randomly selected line numbers. Initial population has $\mu$ individuals.

Step 2: Each individual is defined as $\left(\mathrm{F}_{\mathrm{i}}, \mathrm{L}_{\mathrm{i}}\right)$, where $\mathrm{i}=1,2, \ldots \mathrm{m} . \mathrm{F}_{\mathrm{i}}$ is related the FACTS devices and $\mathrm{L}_{\mathrm{i}}$ related to the line numbers.

Step 3: Calculate the fitness value for each individual $\left(\mathrm{F}_{\mathrm{i}}, \mathrm{L}_{\mathrm{i}}\right)$ by using the objective function from equation 7 .

Step 4: Apply the self-adaptive mutation process for the population. Each parent will generate the new off spring $\left(F_{i}^{*}, L_{i}^{*}\right)$, where $j=1,2 \ldots n$.

$$
\begin{gathered}
F_{i}^{*}(j)=F_{i}+L_{i}(j) N_{i}(0,1) \\
L_{i}^{*}(j)=L_{i}(j) \exp \left(k N_{i}(0,1)+k^{*} N(0,1)\right)
\end{gathered}
$$

Where $\mathrm{N}(0,1)$ denotes the random number which having the mean 0 and standard deviation as 1. $F_{i}(j), F_{i}^{*}(j), L_{i}(j), L_{i}^{*}(j)$ denotes the $j^{\text {th }}$ element form the set of $F_{i}, F_{i}^{*}, L_{i}, L_{i}^{*} . N_{i}(0,1)$ denotes the random number for each value of $\mathrm{J}$. $\mathrm{K}$ and $\mathrm{K}^{*}$ represents the $(\sqrt{ } 2 \sqrt{ } n)^{-1}$ and $(\sqrt{ } 2 n)^{-1}, n$ represents the number of lines.

Step 5: Calculate the fitness function for each offspring $\left(\mathrm{F}_{\mathrm{i}}^{*}, \mathrm{~L}_{\mathrm{i}}^{*}\right)$ by using the objective function from equation 7 .
Step 6: The pair wise comparisons conducted between the parents $\left(\mathrm{F}_{\mathrm{i}}, \mathrm{L}_{\mathrm{i}}\right)$ and offspring's $\left(\mathrm{F}_{\mathrm{i}}^{*}, \mathrm{~L}_{\mathrm{i}}^{*}\right)$.

Step 7: By analysing the comparison values, the optimal pair is selected and it is given a win condition.

Step 8: Stop the generation process if, it reaches to the required optimal value. Otherwise go to step 3.

End

\section{Objectives of the Optimization}

The Parameters that are considered for optimization are branch loading, voltage stability and load minimization [23][24].

\section{1 Branch Loading}

In the power lines, the branch loading maximization is considered as the first optimization problem. If the branch loading of the line is less than $100 \%$, it is equal to 1 and it decreases exponentially with the load. The branch loading is calculated for every line in the power network [25].

$$
\begin{gathered}
\beta=\Pi_{\text {line }} J_{\text {line }} \\
J_{\text {line }}= \begin{cases}e^{\left[\lambda\left(1-\frac{S_{i j}}{S_{i j}^{\max }}\right)\right]} & \text { if } S_{i j}>S_{i j}^{\max } \\
1 & \text { if } S_{i j}^{\max } \geq S_{i j}\end{cases}
\end{gathered}
$$

Where $\beta$ is the branch loading factor, $\lambda$ is equal to 0.1 which is a positive constant, $S_{\mathrm{ij}}$ and $S_{\mathrm{ij}}{ }^{\max }$ are MVA flow and thermal limit from buses $i$ and $j$ in the power lines.

\subsection{Voltage Stability}

The proposed model considers the voltage stability as one of the objectives. To maximize the voltage stability, the following parameters are considered. The voltage stability function is calculated for all the buses in the power network. The optimizing function for voltage stability is equals to 1 . The voltage levels for the power lines range starts from 0.95 p.u. to 1.05 p.u. It is a circuit law to maintain the voltage levels at minimum points. So, the distribution voltage is taken as 0.95 p.u. and the maximum allowable volatage is 1.05 p.u. 


$$
\begin{aligned}
& v=\Pi_{\text {Bus }} J_{\text {Bus }} \\
& J_{\text {Bus }}= \begin{cases}1 & ; \text { if } 1.05 \geq v_{z} \leq 0.95 \\
e^{\left[\mu\left(1-v_{z}\right)\right]} & ; \text { otherwise }\end{cases}
\end{aligned}
$$

Where $\mu$ is equal to 0.1 and it is a positive constant, $v$ is the voltage at bus $\mathrm{z}$.

\subsection{Loss Minimization}

The loss minimization is one of the objective functions for the reactive power. The bus voltage magnitudes and phase angles are managed by the converged load flow solutions. Total network power loss is calculated by the sum of individual line.

$$
J_{l}=\sum_{i=1}^{n} L S_{i}
$$

Where $\mathrm{n}$ is the number of lines participating in the network.

\section{Simulation Results and Discussion}

The proposed model will be simulated in SimPowerSystems or Simulink with MATLAB, to study the Congestion Management. The Flexible AC Transmission Systems (FACTS) optimally uses the Evolutionary Programming Approach.

The parameters considered for Optimization are Branch Loading, Voltage Stability and Loss Minimization. Initial experiments are carried by implementing the normal system without any optimization objective. Initially these parameters are dealt separately and upon obtaining the stable values in subsequent iterations, the proposed model will use the stable result for the next level and the same procedure is followed so that only the population having suitable minimum threshold will be selected. The proposed model is implemented with IEEE30 bus system. Here, It is considering three cases; one is branch loading, second one is voltage stability and the final one is loss minimization.

\section{Case 1: Branch loading with initial population is 200,} 20 generations

In this case, various branches are selected randomly from the normal operating system and loaded with the parameters for checking with and without FACTS devices. Initial population is taken from the normal operating system and selected lines are loaded with a value (say $126 \%$ or so) with and without FACTS device and their values are computed. The results obtained are shown in Table 1. It can be observed that the optimal FACT SVC value is recorded as 5.3926 the optimal FACT TCSC value is noted as 0.3779 and the total loss is 1.0252 . Figure 4 explains about the improvement in the branch loading with optimal placement of TCSC and SVC

Table 1. Branch loading with Evolutionary programming

\begin{tabular}{|l|l|}
\hline \multicolumn{1}{|c|}{ Parameters } & Value \\
\hline Branch loading value & 2267.67 \\
\hline $\begin{array}{l}\text { FACT SVC in the line } \\
\text { number }\end{array}$ & 8 \\
\hline Optimal FACT SVC value & 5.3926 \\
\hline $\begin{array}{l}\text { FACT TCSC in the line } \\
\text { number }\end{array}$ & 14 \\
\hline $\begin{array}{l}\text { Optimal FACT TCSC } \\
\text { value }\end{array}$ & 0.3779 \\
\hline Total Loss & 1.0252 \\
\hline
\end{tabular}

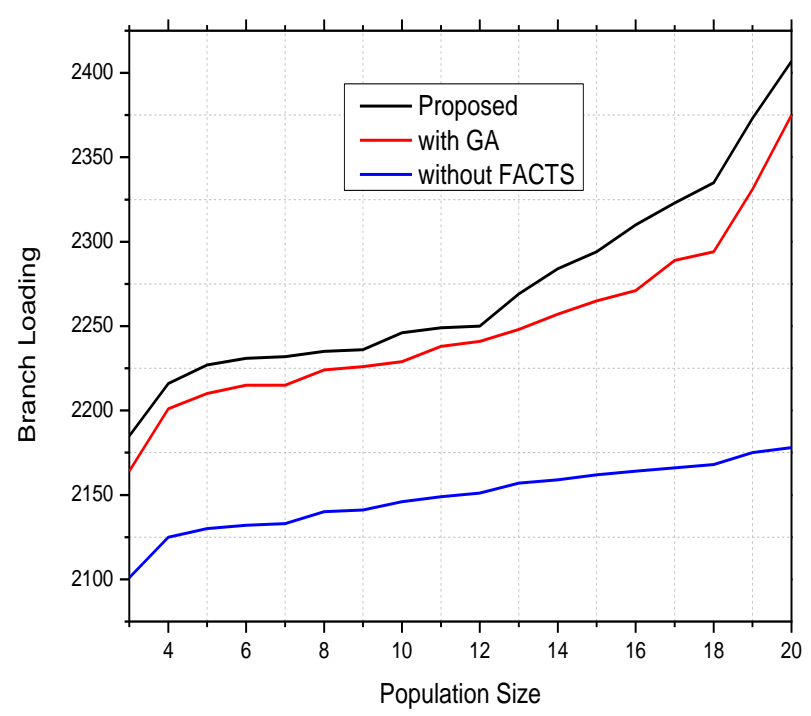

Figure.4 Optimal Branch loading of $126 \%$ with FACTS

Case 2: Voltage Stability with initial population is 200, 20 generations.

In this case, Voltage stability is selected from the normal operating system randomly and loaded with the parameters for checking are with and without FACTS devices. Initial population is taken as 200 from the normal operating system and selected lines are loaded with a value (say $126 \%$ or so) in with and without FACTS device and their values are computed. The results obtained are shown in Table 2. It can be observed that the optimal FACT SVC value is recorded as 0.5242 , the optimal FACT TCSC value is noted as -0.3835 and the total loss is 0.2153 . 
Table 2. Voltage stability using Evolutionary programming

\begin{tabular}{|l|l|}
\hline \multicolumn{1}{|c|}{ Parameters } & Value \\
\hline Voltage Stability value & 1197.43 \\
\hline $\begin{array}{l}\text { FACT SVC in the line } \\
\text { number }\end{array}$ & 20 \\
\hline Optimal FACT SVC value & 0.5242 \\
\hline $\begin{array}{l}\text { FACT TCSC in the line } \\
\text { number }\end{array}$ & 14 \\
\hline $\begin{array}{l}\text { Optimal FACT TCSC } \\
\text { value }\end{array}$ & -0.3835 \\
\hline Total Loss & 0.2153 \\
\hline
\end{tabular}

Figure 5 explains about the maximization of voltage stability with optimal placement of TCSC and SVC.

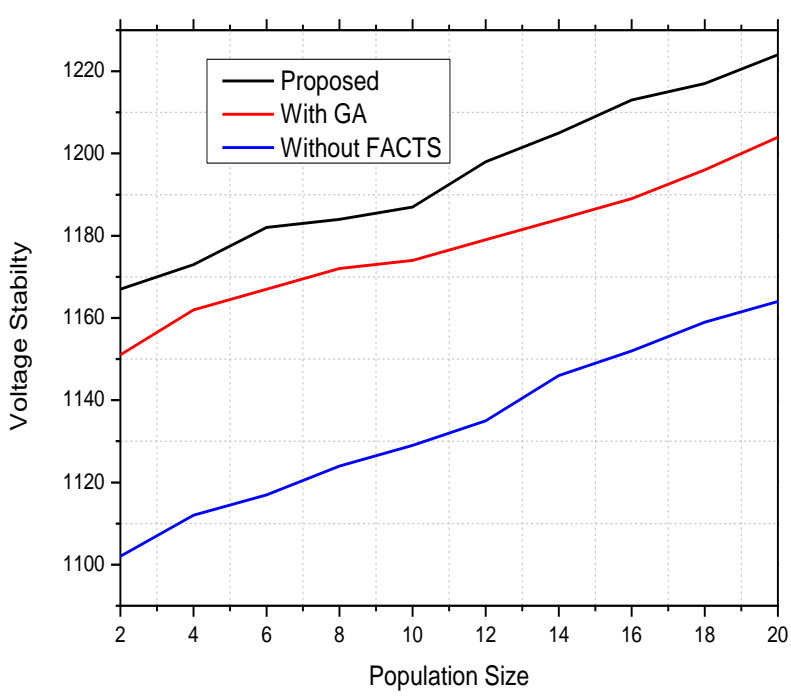

Figure.5 Maximizing voltage stability for uniform loading of $126 \%$ with FACTS

Case 3: Loss Minimization with initial population is 200, 20 generations.

In this case, Loss minimization is selected as the objective of the EP and the parameters for checking are with and without FACTS devices. Initial population is taken as 200 from the normal operating of the system and selected lines are loaded with a value (say $126 \%$ or so) in with and without FACTS device and their values are computed. The results obtained are shown in Table 3. It can be observed that the optimal FACT SVC value is recorded as 0.1615, the optimal FACT TCSC value is noted as 0.3779 and the total loss is 6.4201 .

Figure 6 explains about the minimization of power loss with optimal placement of TCSC and SVC.
Table 3. Loss Minimization using Evolutionary programming

\begin{tabular}{|l|l|}
\hline \multicolumn{1}{|c|}{ Parameters } & Value \\
\hline Branch loading value & 2069.14 \\
\hline Voltage Stability Value & 1034 \\
\hline $\begin{array}{l}\text { FACT SVC in the line } \\
\text { number }\end{array}$ & 18 \\
\hline Optimal FACT SVC value & 0.1615 \\
\hline $\begin{array}{l}\text { FACT TCSC in the line } \\
\text { number }\end{array}$ & 9 \\
\hline $\begin{array}{l}\text { Optimal FACT TCSC } \\
\text { value }\end{array}$ & 0.3779 \\
\hline Total Loss & 6.4201 \\
\hline
\end{tabular}

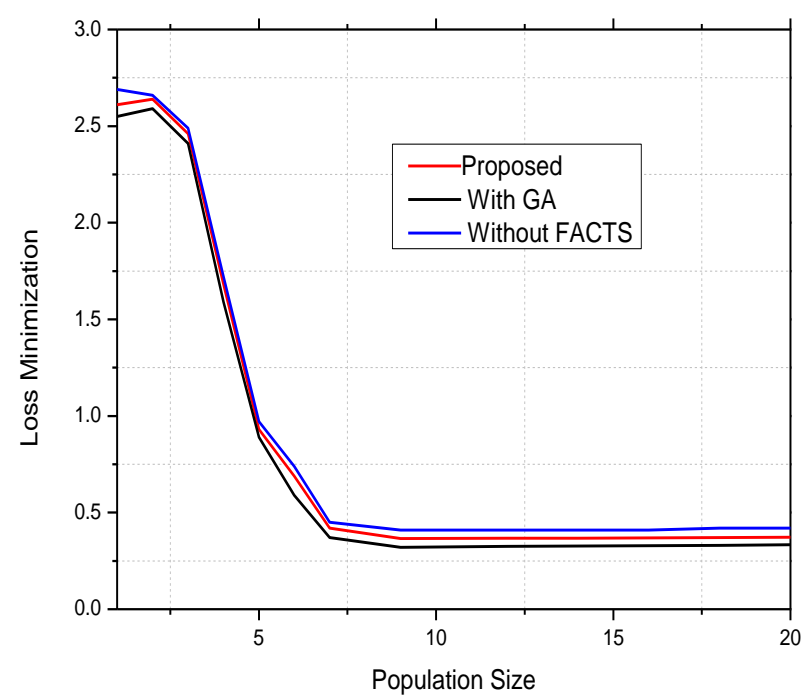

Figure.6 Loss Minimization for uniform loading of $126 \%$ with FACTS

Comparison of Best compromising solution with FACTS using the Evolutionary Programming and Genetic algorithm:

With the simultaneous operations of branch loading voltage stability and loss minimization, the branch loading is increased by $9.6 \%$ and the voltage stability is increased by $2.3 \%$ and the loss is reduced by $4.8 \%$. The evolution programming algorithm outperforms the genetic algorithm and the results obtained for both GA and evolutionary programming are shown in Table 4. 
Table 4. Performance measurement of GA and Evolutionary Programming

\begin{tabular}{|l|l|l|c|}
\hline Parameters & $\begin{array}{l}\text { Base } \\
\text { case }\end{array}$ & $\begin{array}{l}\text { Genetic } \\
\text { Algorith } \\
\text { m }\end{array}$ & $\begin{array}{l}\text { Evolutionary } \\
\text { Programmin } \\
\text { g }\end{array}$ \\
\hline $\begin{array}{l}\text { Branch } \\
\text { loading }\end{array}$ & $\begin{array}{l}2267.6 \\
7\end{array}$ & 2375.12 & 2425.24 \\
\hline $\begin{array}{l}\text { Voltage } \\
\text { Stability }\end{array}$ & 1197.4 & 1205.36 & 1224.87 \\
\hline $\begin{array}{l}\text { Loss } \\
\text { Minimizatio } \\
\text { n }\end{array}$ & 0.4213 & 0.3876 & 0.2941 \\
\hline
\end{tabular}

\section{Conclusion}

In this paper, evolutionary programming algorithm for optimal positioning of FACTS device in power network was proposed. The proposed approach considered the different objectives for regulating the power supply. The algorithm is tested with different combinations of transmission lines and FACTS devices. The algorithm considers branch loading, voltage stability and the loss minimization as the optimization objectives. The results are tested with IEEE30 bus system and the population is taken as 200 with 20 generations. The proposed evolutionary programming approach performs well when compared to the conventional GA in reducing the congestion by considering the objectives. In the future, the proposed approach is analysed with smart grid environment for better optimization.

\section{References}

[1] H. Singh, H. Shangyou and P. Alex. "Transmission congestion management in competitive electricity markets", IEEE Trans Power Syst, pp. 672-80,1988.

[2] P. N. Biskas and A. G. Bakirtzis. "Decentralised congestion management of interconnected power systems", IEEProceedings-Generation, Transmission and Distribution, pp. 432-438, 2002.

[3] N. Nadarajah, and A. Naresh. "A proposal for investment recovery of FACTS devices in deregulated electricity markets." Electric Power Systems Research, Vol. 77, No. 5, pp. 695-703, 2007.

[4] T. Seyed Abbas and H. Besharat, "Transmission congestion management by determining optimal location of FACTS devices in deregulated power systems." American Journal of Applied Sciences, Vol. 5, No. 3, pp. 242-247, 2008.

[5] A. Naresh, and N. Mithulananthan. "Locating series FACTS devices for congestion management in deregulated electricity markets." Electric power systems research, Vol. 77, No. 3, pp. 352-360, 2007.
[6] S. N. Singh and A. K. David. "Optimal location of FACTS devices for congestion management." Electric Power Systems Research, Vol. 58, No. 2, pp. 71-79, 2001.

[7] L. J. Cai, I. Erlich, and G. Stamtsis. "Optimal choice and allocation of FACTS devices in deregulated electricity market using genetic algorithms." Power Systems Conference and Exposition, 2004. IEEE PES. IEEE, 2004.

[8] S. Gerbex, C. Rachid and A. J. Germond. "Optimal location of multi-type FACTS devices in a power system by means of genetic algorithms." IEEE transactions on power systems, Vol. 16, No. 3, pp. 537-544, 2001.

[9] W. Lin and S. Chen. "Bid-based dynamic economic dispatch with an efficient interior point algorithm." International journal of electrical power \& energy systems, Vol. 24, No. 1, pp. 51-57, 2002.

[10] L. Rajalakshmi,, M.V. Suganyadevi and S. Parameswari. "Congestion management in deregulated power system by locating series FACTS devices', International journal of Computer applications, Vol. 13, pp.0975-8887, 2011.

[11] S.V.V. Luis, V. H. Quintana, and V. Anthony. "A tutorial description of an interior point method and its applications to security-constrained economic dispatch." IEEE Transactions on Power Systems, Vol. 8, No. 3, pp.1315-1324, 1993.

[12] K. Vijayakumar, "Optimal location of FACTS devices for congestion management in deregulated power systems." International Journal of Computer Applications, Vol. 16, No. 6, pp. 29-37, 2011.

[13] J. Baskaran. "Genetic Algorithm and Fuzzy logic based optimal location of FACTS device in a power system network." International Journal of Emerging Electric Power Systems, Vol. 5, No. 2, 2006.

[14] S. Sutha and N. Kamaraj. "Optimal location of multi type facts devices for multiple contingencies using particle swarm optimization." electrical engineering, 2008.

[15]K. Balamurugan, V.Dharmalingam, R. Muralisachithanandam and R. Sankaran. "Differential Evolution Based Optimal Choice and Location of Facts Devices in Restructured Power System." World Academy of Science, Engineering and Technology, International Journal of Electrical, Computer, Energetic, Electronic and Communication Engineering, Vol. 7, No. 2, pp. 229-237, 2013.

[16]K. Balamurugan, R. Muralisachithanandam, V. Dharmalingam and R. Srikanth, "Optimal choice and location of multi type facts devices in deregulated electricity market using evolutionary programming 
method", Int. J. Electr. Electron. Sci. Eng, Vol. 7, pp.96-102, 2013.

[17] G. Suganya, K. Balamurugan, and V. Dharmalingam. "Multi-objective evolutionary programming technique for economic/emission load dispatch." Advances in Engineering, Science and Management (ICAESM), 2012 International Conference on. IEEE, 2012.

[18]E. Akram, A. Eladl, and J. Morrow. "Long-term economic model for allocation of FACTS devices in restructured power systems integrating wind generation." IET Generation, Transmission \& Distribution, Vol. 10, No. 1, pp.19-30, 2016.

[19] H. Patel and P. Ravikumar. "Congestion management in deregulated power system using FACTS deveices, "International Journal of Advances in Engineering \& Technology, Vol. 8, No. 2,pp.175-179, 2015.

[20] K. Singh, Y. Vinod Kumar, P. Narayana Prasad, and S. Jaydev. "Congestion management considering optimal placement of distributed generator in deregulated power system networks." Electric Power Components and Systems, Vol. 42, No. 1, 13-22, 2014.

[21]Z. Mohd, A. Asuhaimi, M. Moradi, A. Khairuddin, and M. Moradi. "An Analytical Literature Review of the Available Techniques for Relieving Transmission Line Bottleneck in Deregulated Power Systems." In Applied Mechanics and Materials, Vol. 818, pp. 124128. 2016.

[22]B. Harvard, K. Mugdha, and S. Gurav. "Genetic algorithm based optimal allocation of SVC for reactive power minimization in power systems." Industrial Instrumentation and Control (ICIC), 2015 International Conference on. IEEE, 2015.

[23]H. G. Amulya, T. M. Vasanth Kumar, and K. R. Mohan. "Application of PSO and GA in Optimal Placement of FACTS devices in Transmission line." (2014).

[24]J. A. Rezaee. "Brainstorm optimisation algorithm (BSOA): An efficient algorithm for finding optimal location and setting of FACTS devices in electric power systems." International Journal of Electrical Power \& Energy Systems, Vol. 69, pp. 48-57, 2015.

[25] A. Elmitwally and A. Eladl. "Planning of multi-type FACTS devices in restructured power systems with wind generation." International Journal of Electrical Power \& Energy Systems, Vol. 77, pp. 33-42, 2016.

[26]S. Gerbex, R. Cherkaoui, and A. J. Germond, "Optimal location of multitype FACTS devices in a power system by means of genetic algorithms," IEEE Trans. Power Systems, Vol. 16, pp. 537-544, 2001. 